\title{
Team-sport training is a worthy alternative to fitness training for sedentary women with lifestyle diseases in a community health centre set-up
}

Møller, Trine Kjeldgaard ${ }^{1}$; Nielsen, Tina-Thea ${ }^{2,3}$; Lundager, $\mathrm{Ida}^{2}$, Andersen, Rene $^{2}$; Krustrup, Peter ${ }^{1,4,5}$ and Randers, Morten Bredsgaard ${ }^{1,6}$

${ }^{1}$ Department of Sports Science and Clinical Biomechanics, SDU Sport and Health Sciences Cluster (SHSC), University of Southern Denmark, Odense, Denmark.

${ }^{2}$ Department of Nutrition, Exercise and Sports, University of Copenhagen, Copenhagen, Denmark.

${ }^{3}$ University College Copenhagen, Copenhagen, Denmark.

${ }^{4}$ Sport and Health Sciences, University of Exeter, Exeter, United Kingdom.

${ }^{5}$ Shanghai University of Sport, Shanghai, China.

${ }^{6}$ School of Sport Sciences, Faculty of Health Sciences, UiT The Arctic University of Norway, Tromsø, Norway

Short title: Effectiveness of training for sedentary women in a community health centre set-up

\section{Corresponding author:}

Morten Bredsgaard Randers

Department of Sports Science and Clinical Biomechanics

Faculty of Health Sciences

University of Southern Denmark

Campusvej 55, Odense M-3450, Denmark

mranders@health.sdu.dk

Tel.: 004565504863 


\begin{abstract}
This study aimed to examine the health effects of fitness training and team-sport training in a pragmatic community health centre set-up for women with lifestyle diseases. The methods included training intensity evaluations and measurements of $\mathrm{VO}_{2} \max$, blood pressure, body composition and exercise performance. Forty women in the fitness training group (FG) and 34 women in the team-sport training group (TG) completed pre- and post-tests, after they were offered 12-16 weeks of twice-weekly training sessions lasting 60-90 min. Mean heart rate during training was not significant different $(\mathrm{P}=0.569)$ between $\mathrm{FG}\left(72.7 \pm 4.2 \% \mathrm{HR}_{\max }\right)$ and $\mathrm{TG}$ $\left(71.4 \pm 6.8 \% \mathrm{HR}_{\max }\right) . \mathrm{TG}$ achieved improvements in aerobic fitness of $0.9 \pm 2.0 \mathrm{mlO} 2 \cdot \mathrm{kg} \cdot \mathrm{min}^{-1}$ $(\mathrm{P}=0.034)$ and in resting heart rate of $3.7 \pm 9.1 \mathrm{bpm}(\mathrm{P}=0.026)$, as well as in sit-to-stand performance (STS: $3.5 \pm 3.3 \mathrm{stands} \cdot 30 \mathrm{sec}^{-1} ; \mathrm{P}=0.003$ ) and 6-min walking test performance (6MWT: $53 \pm 29 \mathrm{~m} ; \mathrm{P}<0.001)$, while fat percentage was reduced by $0.6 \pm 1.6 \%(\mathrm{P}=0.038)$. FG achieved within-group improvements $(\mathrm{P}<0.001)$ in STS performance $\left(3.1 \pm 2.8\right.$ stands $\left.\cdot 30 \mathrm{sec}^{-1}\right)$ and $6 \mathrm{MWT}$ performance $(41 \pm 47 \mathrm{~m})$, with fat percentage reduced by $0.9 \pm 1.7 \%(\mathrm{P}=0.003)$. Overall, the study revealed no significant between-group differences in training effects. However, there was a between-group difference in training attendance $(\mathrm{P}=0.001)$, with the fitness group having the highest attendance ( $1.5 \pm 0.4$ vs. $1.1 \pm 0.5$ per week). In conclusion, small-sided team-sport training and fitness training conducted in a pragmatic set-up induce similar positive health effects for women with lifestyle diseases. Team-sport training is considered a feasible and worthy alternative to fitness training for sedentary women in community health centres.
\end{abstract}

Key words: $\mathrm{VO}_{2} \max$, body composition, exercise intensity, performance, small-sided activities 


\section{INTRODUCTION}

It is well-documented that physical activity is of major importance for preventing and treating lifestyle diseases, and thereby improving public health (26). In Denmark, community health centres (CHCs) offer physical training for citizens referred by a general practitioner (GP) for physical activity as a part of their treatment for lifestyle diseases.

Ageing individuals are not only able to maintain their physical capacity, body composition and, consequently, performance in activities of daily living and quality of life $(1,11)$, but can also benefit from physical activity in terms of the prevention and treatment of lifestyle diseases (26). To support the edification of an active lifestyle and long-term continuance of physical activity, it is important to develop health-enhancing exercise that is feasible for implementation in CHCs. In relation to health-related outcomes, randomised, controlled studies show that, for overweight, middle-aged women, resistance training and aerobic training are equally effective for altering fat percentage (9). For post-menopausal women, physical activity is also a major determinant for maintaining muscle mass and reducing the accumulation of, in particular, intramuscular fat (18). Moreover, age-related decline in muscle strength can have a significant effect on functional performance, and studies show that women experience a $21 \%$ decrease in muscle strength between the age of 25 and 55 (2).

Citizens who are prescribed exercise struggle to maintain a healthier lifestyle and increased levels of physical activity after a period of supervised training involving classic individual activities such as strength training or running/cycling (31). Recent studies have shown that team-sport activities, such as recreational football, can promote long-term adherence to physical activity, probably due to the fact that these activities are considered joyful, fun and social, in contrast to the fitness training traditionally used in CHC set-ups $(23,25)$. Moreover, interventions involving recreational, small-sided team-sport training has shown broad-spectrum health effects for untrained women (17). The intermittent nature of small-sided football 
games can stimulate the cardiovascular system and musculoskeletal and metabolic fitness by virtue of high heart rates, high numbers of intense accelerations and decelerations, and repeated changes in direction $(17,28)$. We therefore sought to implement team-sport activities in the community health centre set-up with an activity profile comparable to that of small-sided teamsport. A parallel study with untrained men, showed improved performance in physical performance tests and lowered blood pressure and fat mass after team-sport training and standard CHC fitness training (22).

This study aimed: 1) to measure the health effects of standard CHC fitness training in participants with one or more lifestyle diseases, namely hypertension, cardiovascular disease, type 2 diabetes, chronic obstructive pulmonary disease (COPD) and/or obesity, 2) to examine whether it was possible to conduct team-sport activities in a pragmatic, real-life set-up, in contrast to the highly controlled studies previously conducted in laboratories, and measure the health effects on $\mathrm{CHC}$ participants, and 3) to compare developments in the health parameters of the participants in standard fitness training and team-sport training. 


\section{METHODS}

\section{Experimental approach to the problem}

The study aimed to examine whether the results of randomised, controlled trials can be repeated at a specific location in the Municipality of Copenhagen. The design therefore adopted a pragmatic, real-life approach to the daily context of work for the employees at the $\mathrm{CHC}$. The $\mathrm{Mu}-$ nicipality of Copenhagen, the $\mathrm{CHC}$ and the research group at the University of Copenhagen aimed to examine the physiological effects of the fitness training under the habitual standard procedures (see below). Furthermore, the aim was to examine whether it was possible to conduct team-sport training under these standard procedures and examine possible physiological effects of team-sport training. The standard CHC procedures included continuous inclusion of citizens referred by their GP, use of the employed physiotherapists as instructors and all training conducted at or in relation to the $\mathrm{CHC}$ facility. The $\mathrm{CHC}$ facility was a $10 \times 10 \mathrm{~m}$ gym in which essentially all training was conducted. The gym was equipped with machines for strength and cardio training during the fitness intervention and subsequently cleared for the team-sport intervention. Furthermore, the $\mathrm{CHC}$ offered only one training programme at a time. Therefore, randomisation was not possible, and the interventions were carried out in two consecutive years.

To study the effects of the standard fitness training conducted in the CHC, participants for the fitness group (FG) were recruited and trained during the first year. In the second year, the standard fitness training sessions were replaced with team-sport training (TG), and the participants for this group were recruited and trained during the second year.

All referred female citizens with lifestyle diseases such as hypertension, dyslipidaemia, type 2 diabetes or obesity, or at risk of developing these diseases, were offered the opportunity to participate in the study. 
The physiotherapists informed the citizens about the project and invited them to an information meeting hosted by a representative of the scientific group. The training programme was the same (year 1 fitness and year 2 team-sport training) for all citizens, regardless of whether they participated in the study. Citizens were allocated to training groups consisting of 12 citizens, and each group included both citizens participating in the study and those not participating. Because of the standard continuous inclusion in the training group, the training periods for all 12 citizens in a group had different start dates. Nearly all training groups included both men and women, except for one training group for women who preferred a gender-specific training group.

Potential participants were informed of the risks associated with the experiment before giving their informed, written consent to participate. The study conformed to the Code of Ethics of the World Medical Association (Declaration of Helsinki) and was approved by the Ethics Committee of Copenhagen (H-1-2014-014).

Figure 1 about here. 


\section{Participants}

A total of 125 sedentary women participated in the study; 63 in FG and 62 in TG. Fifty-one women dropped out of the study (FG: 23, TG: 28). Thus, a total of 74 women completed the study (FG: 40, TG: 34 ). The recruitment process at the $\mathrm{CHC}$ and drop out causes are described in Figure 1.

Results from the baseline tests were alike between the two groups, apart from better performance $(\mathrm{P}=0.048)$ in the balance test by $\mathrm{TG}$ than by FG. Furthermore, the baseline data in TG was similar for all participants, applicable for those participants who completed the training period and those who dropped out. In FG, participants who completed the training period had better baseline performance in the sit-to-stand test (STS) than participants who dropped out ( $14 \pm 4$ vs $11 \pm 4$ stands/30s, $\mathrm{P}=0.033)$.

The CHC was obliged to offer training to all referred citizens, so there were no exclusion and inclusion criteria. Nevertheless, the researchers did not perform selected measurements that involved a high risk to the participant (incremental cycle test to exhaustion for participants with BP $>180 / 110 \mathrm{mmHg}$ ) or the equipment (DXA scans for participant $>180 \mathrm{~kg}$ ). Each participant was offered 12 weeks of training involving twice-weekly 90 -min sessions, except for participants in the obesity group (BMI>35) (FG: $N=4$; $T$ : $N=4)$, who were offered 16 weeks of training involving twice-weekly 60 -min sessions - according to CHC standards.

Blood pressure values from participants with altered antihypertension medicine use during the intervention period were removed from the blood pressure, resting heart rate and training intensity analysis. For the distribution of participant referral causes, see Table 1.

\section{Procedures}




\section{Training}

Physiotherapists employed at the CHC carried out the training for both groups. At the end of year one, the physiotherapists attended a workshop organised by scientific employees of the Copenhagen Centre for Team Sport and Health, University of Copenhagen, to define the content of the team-sport training and educate the physiotherapists in conducting small-sided teamsport training. Based on this workshop, a group of CHC staff members developed a Team Sport Manual of games and possible adjustments for use during training. Team-sport training was conducted indoors, with the games adjusted to the facilities. The training attendance rate was higher $(\mathrm{P}=0.001)$ for $\mathrm{FG}$ than for $\mathrm{TG}(74 \pm 21 \%$ vs $53 \pm 25 \%)$, with $1.5 \pm 0.4$ and $1.1 \pm 0.5$ training sessions per week for FG and TG, respectively. A total of 55 observations of training sessions were conducted (FG: $\mathrm{N}=21$; $\mathrm{TG}: \mathrm{N}=34$ ), and measurements of heart rate (HR) and rating of perceived exertion (RPE) on a visual analogue scale (VAS) specific to legs and respiration were performed on 35 participants (FG: $\mathrm{N}=11$; $\mathrm{TG}$ : $\mathrm{N}=24$ ).

\section{Physiological test procedures}

The test protocol is described in detail in Møller et al. (2018). Briefly, the participants were tested on two separate days, before and after the training period. The test battery on day 1 included whole-body fat mass, muscle mass (LBM), bone mass (BMC) and bone density (BMD) determined by DXA scans (LUNAR, GE Medical Systems, US), blood pressure (HBP1300; OMRON, Illinois, USA), resting heart rate (RHR; OMRON HBP-1300; Polar System, Polar Electro Oy, Kempele, Finland) and an incremental cycle test to exhaustion measuring pulmonary gas exchange (Masterscreen CPX, CareFusion, Germany) to determine maximal aerobic fitness $\left(\mathrm{VO}_{2} \mathrm{max}\right)$. All physiological tests were conducted at the University of Copenhagen by exercise physiologists. On test day 2 , the participants performed three standardised performance tests: a STS test performed to test the participants' ability to perform repeated 
standing-up from a chair; a tandem balance test (20); and a 6-min walking test (6MWT). The performance tests were conducted at the $\mathrm{CHC}$ by the physiotherapists according to their standard procedure before and after the training period.

\section{Measurements during training}

HR was recorded at $5 \mathrm{~s}$ intervals by short-range radio telemetry (Polar Team 2 System, version 1.4.5 Polar Electric Oy, Kempele, Finland). Data are expressed in relation to individual maximal heart rate $\left(\mathrm{HR}_{\max }\right)$ and in $\mathrm{HR}$ zones $<70,70-80,80-90$ and $90-100 \%$ of $\mathrm{HR}_{\max }$. HR recordings with technical errors were removed before analysis. Individual $\mathrm{HR}_{\max }$ was determined as the highest value reached either during an incremental cycle test to exhaustion or during training.

\section{Physiological tests}

Whole-body fat mass and lean body mass (LBM) were determined by DXA scans (LUNAR, GE Medical Systems, USA). Blood pressure was measured at least six times by an automatic upper-arm blood-pressure monitor (HBP-1300; OMRON, Illinois, USA) and an average value was calculated. Resting heart rate (RHR) was measured by OMRON HBP-1300 and Polar System, and the lowest recorded value was used. Pulmonary gas exchange (Masterscreen CPX, CareFusion, Germany) was recorded at $5 \mathrm{~s}$ intervals during the incremental cycling test to exhaustion to determine maximal aerobic fitness $\left(\mathrm{VO}_{2} \mathrm{max}\right)$. Participants started exercising at a self-chosen pace of $>50 \mathrm{rpm}$ and a load of $40 \mathrm{~W}$, and after a 2-min period the workload was increased by $10 \mathrm{~W}$ every $30 \mathrm{~s}$ until voluntary exhaustion. $\mathrm{VO}_{2} \max$ was determined as the highest value achieved during a 30-s period. A respiratory exchange ratio (RER) of minimum 1.05 in combination with/or a levelling off was set to determine the level of maximal oxygen uptake (34). 


\section{Performance tests}

Test day 2 involved following: (1) The participants performed a sit-to-stand (STS) test to determine their ability to perform repeated standing-up from a chair. Using a chair with a seat height of $45 \mathrm{~cm}$, the participants were instructed to sit in the middle of the chair with back straight, arms crossed over chest and feet flat on the floor. The participants were given a demonstration and practised one to two repetitions before the start of the test. On the signal "go", the participant rose to a full standing position, then returned to a seated position, repeating this as many times as possible in $30 \mathrm{~s}$. (2) the participants performed a tandem balance test (24) involving four levels (duration $4 \times 10 \mathrm{~s}$ ), each resulting in $0-10$ points (seconds). The four levels included standing up for $10 \mathrm{~s}$ with parallel feet, feet in semi-tandem position, full tandem position with open eyes, and full tandem position with closed eyes. There was a maximum achievement of $40 \mathrm{~s}$. Participants who scored a total of $40 \mathrm{~s}$ in the baseline test were therefore removed from analysis. (3) The participants performed a 6-min walking test, walking for 6 min on a $25-\mathrm{m}$ indoor track with a cone as a turning point at each end. They were instructed to walk as fast as possible during the test. If the participant felt the need to take a break, they were instructed to do this standing and, if necessary, supporting themselves against the wall.

\section{Statistical analysis}

Baseline and post-intervention data were tested for within-group effects with a paired-samples t-test. Between-group effects were tested with univariate variance analysis using change scores as dependent value, baseline values as covariate and group as factor. Between-group effects in intensity during training were compared with an independent-samples Mann-Whitney U test, and between-group differences in attendance and VAS scores were tested with one-way 
ANOVA. In FG and TG, respectively, baseline differences between participants who completed the training and drop-outs were tested with one-way ANOVA. All statistics were run in IBM SPSS statistics 24. A significance level of 0.05 was chosen. Data are presented as means $\pm \mathrm{SD}$ or change scores $(95 \%$ confidence interval $(\mathrm{CI})$ ). Time spent in intensity zones is presented as median (inter-quartile range (IQR)).

\section{RESULTS}

\section{Within-group changes}

\section{Aerobic fitness}

Expressed relative to body mass, there were no significant change in aerobic fitness in FG $\left(19.4 \pm 4.2\right.$ to $\left.20.1 \pm 4.1 \mathrm{mlO} \cdot \mathrm{kg} \cdot \mathrm{min}^{-1}, \mathrm{P}=0.277\right)$, whereas it increased in $\mathrm{TG}(18.6 \pm 5.4$ to $\left.19.5 \pm 5.2 \mathrm{mlO}_{2} \cdot \mathrm{kg} \cdot \mathrm{min}^{-1}, \mathrm{P}=0.034\right)$ (Table 1).

\section{Blood pressure}

There was no significant change in blood pressure and RHR in FG. In TG, blood pressure was not significantly changed (Table 1$)$, but RHR was lowered $(\mathrm{P}=0.026)$ from $68 \pm 10$ to $64 \pm 9 \mathrm{bpm}$.

\section{Body composition}

In $\mathrm{FG}$, total fat mass decreased $(\mathrm{P}=0.005)$ from $40.4 \pm 10.9$ to $39.5 \pm 11.2 \mathrm{~kg}$ and tended to decrease $(\mathrm{P}=0.065)$ in $\mathrm{TG}$ from $44.0 \pm 14.7$ to $43.2 \pm 13.8 \mathrm{~kg}$. Fat percentage decreased $(\mathrm{P}=0.003)$ from $44.5 \pm 5.0$ to $43.7 \pm 5.9 \%$ in $\mathrm{FG}$ and from $46.1 \pm 8.3$ to $45.6 \pm 8.9 \%$ in $\mathrm{TG}(\mathrm{P}=0.038)$. There was no significant change in LBM in either FG or TG (Table 1). 
Whole-body BMD decreased ( $\mathrm{P}=0.037)$ from $1.177 \pm 0.119$ to $1.173 \pm 0.117 \mathrm{~g} / \mathrm{cm}^{2}$ in $\mathrm{FG}$ whereas there was no significant change in TG. There were also no significant changes in BMC for whole body, or in BMC and BMD for legs, in FG or TG (Table 1).

\section{Physiological response to training}

Relative heart rate during training was $72.7 \pm 4.2 \%$ of $\mathrm{HR}_{\max }$ in $\mathrm{FG}$ and $71.4 \pm 6.8 \%$ of $\mathrm{HR}_{\max }$ in TG. The participants rated general perceived exertion at $6.3 \pm 2.4(95 \% \mathrm{CI} 4.2,8.3)$ in FG and $5.0 \pm 2.3(95 \%$ CI $3.8,6.2)$ in TG on a $0-10$ - point visual analogue scale (VAS). Specified values for RPE for legs and respiration were 5.5 \pm 2.7 (95\% CI 3.2, 7.8) and 6.4 $\pm 2.2(95 \% \mathrm{CI} 4.5,8.2)$, respectively, in FG and 3.0 2.0 (95\% CI 1.9, 4.0) and 5.0 2.6 (95\% CI 3.6, 6.3), respectively, in TG.

\section{Functional performance}

In the STS test, improvements were observed in both FG $(14 \pm 4$ to $17 \pm 5$ stands, $\mathrm{P}<0.001)$ and TG ( $14 \pm 4$ to $17 \pm 5$ stands, $\mathrm{P}=0.003)$. In $6 \mathrm{MWT}, \mathrm{FG}$ improved performance by $41 \mathrm{~m}(481 \pm 78$ to $523 \pm 88 \mathrm{~m}, \mathrm{P}<0.001)$ and TG by $53 \mathrm{~m}(487 \pm 88$ to $540 \pm 89 \mathrm{~m}, \mathrm{P}<0.001)$. In the balance test, performance improved in FG ( $31 \pm 6$ to $35 \pm 6 \mathrm{~s}, \mathrm{P}=0.02$ ), but not significantly in TG (Table 1$)$.

Table 1 around here

\section{Between-group differences}

There were no significant between-group differences in either primary or secondary health-related outcomes (Table 2). In respect of physiological response to training, no significant between-group differences were observed in the relative heart rate during training or for time spent in any of the heart rate zones $<70,70-80,80-90$ and $90-100 \%$ of $\mathrm{HR}_{\max }$ (Fig. 2). 
There was a between-group effect for the specified RPE for legs $(\mathrm{P}=0.014)$, with a lower RPE for legs in TG than in FG.

In FG, the attendance rate was higher $(73.8 \%$; $95 \%$ CI $66.7,80.9)$ than in TG $(53.1 \%$; 95\% CI 44.0, 62.2) (Table 2).

Figure 2 around here

Table 2 around here

\section{Adverse events}

In TG one adverse event was reported during training. The participant sustained a calf strain which caused 20 days of non-attendance. No adverse events were reported in FG during the 12-16 week intervention period.

\section{DISCUSSION}

The main finding of the present study was that both fitness training and team-sport resulted in positive developments in several health-related outcomes, with similar training responses in the two intervention groups. In FG, fat mass, fat percentage, STS and 6MWT performance improved. In TG, aerobic fitness, RHR, fat percentage, STS performance and 6MWT performance improved. Moreover, this study showed that it is possible to conduct team-sport training in a standard CHC set-up. No significant between-group differences were found in any of the test variables. There was a between-group difference in training attendance, which was lower for TG than for FG. Furthermore, it was observed that the participants felt that team-sport training was less strenuous for the legs than fitness training.

\section{Within-group changes}

Aerobic fitness improved slightly in both groups (FG, non-significant). Other studies show that low cardiorespiratory fitness is a major predictor of death and increases the risk of 
several non-communicable diseases (26). The study by Aspenes et al. (3) found an unfavoura-

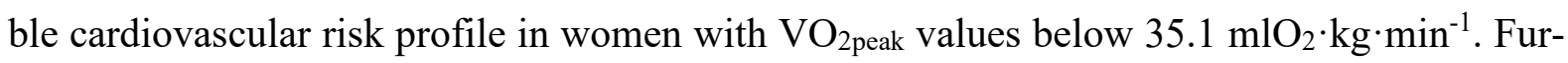
thermore, the study specified that every $5 \mathrm{mlO}_{2} \cdot \mathrm{min}^{-1}$ below this threshold correspond to a $56 \%$ higher prevalence of cardiovascular risk factor clustering (3). With low baseline values in aerobic fitness of $\sim 19 \mathrm{mlO}_{2} \cdot \mathrm{kg} \cdot \mathrm{min}^{-1}$ in the present study, any improvement in aerobic fitness is of relevance.

In the present study, there was a small reduction in RHR (FG, non-significant). The reduction was in line with a similar decrease in RHR for untrained women found by Krustrup and colleagues after 4 months of recreational football (14). Combined, the small improvements in aerobic fitness and RHR signify a more favourable health profile for the participants compared to baseline values.

Meanwhile, the change in aerobic fitness after team-sport training is at the lower end of what has previously been observed in team-sport training for women $(4,8,16,29)$. As seen in the parallel study involving male participants (22), a reasonable explanation for the difference in the effect on aerobic fitness between other studies on team-sport training $(17,29)$ and the present study is the markedly lower training intensity. This is also in line with a systematic review and meta-analysis by Weston and colleagues (2014), who found that cardiorespiratory fitness in patients with lifestyle-induced chronic diseases was increased after high-intensity interval training by almost double compared to moderate-intensity continuous training (32).

Furthermore, the potential improvements in cardiovascular risk factors were affected by the low training attendance in the present study $(1.5 \pm 0.4$ and $1.1 \pm 0.5$ weekly training sessions for FG and TG, respectively). In respect of health-related benefits, the recommendations for training volume are considerably higher (>150 min/week, moderate intensity) $(10,12)$. Although studies in middle-aged sedentary women (29) and men (5) have shown improvements in cardiovascular risk factors such as aerobic fitness after a similar training period with only 
one weekly training session, as in the present study, the training intensities in these studies (29, 5) were considerably higher than in the present study.

In the present study, blood pressure was not significantly changed in either group. Møller and colleagues (2018) found that low baseline levels and a lower training intensity, compared to other studies of small-sided team-sport activities, was a reasonable cause for the less distinct effect on blood pressure than seen in other studies (22). In the present study, the female participants in TG had markedly lower training intensity and adherence than the male participants, and this could explain why there were no changes in blood pressure. Although a meta-analysis (20) has shown positive effects of recreational football on blood pressure, other studies involving normotensive individuals (as in the present study) have not found any effect on blood pressure after either recreational football nor continuous running after 4 and 16 months of training (14) or after 16 weeks of twice-weekly 15 -min recreational football training sessions (7). It is therefore possible that the training outcomes in TG were affected by baseline values in the normal range and the overall small training volume with low adherence.

It is well established that obesity is a risk factor for several chronic diseases $(26,33)$. A majority of the participants in the present study were obese, with an average baseline BMI of $\sim 35 \mathrm{~kg} / \mathrm{m}^{2}$ and a fat percentage of $\sim 45 \%$. Both training interventions induced a small reduction in fat percentage (FG: $-0.9 \%$ and TG: $-0.4 \%$ (borderline significance. $\mathrm{P}=0.065$ )). In studies in women using aerobic endurance training and resistance training (9) or using small-sided football training and running (14), fat percentage was not lowered, which is in line with the small reductions in the present study. The reduction in TG was smaller than seen in a study by Mohr et al. (2014) in which untrained women trained using recreational football for 15 weeks. Mohr and colleagues found a reduction of $2.3 \mathrm{~kg}(2.1 \%)$, but the estimated weekly energy expenditure in the present study was approximately three times lower compared to the study by Mohr and colleagues, in which the participants trained at higher intensity than in the present study. This 
may partly explain the relatively smaller reduction in fat percentage in the present study. For men completing the same training, the reduction in fat mass was $1.6(\mathrm{FG})$ and $0.9 \mathrm{~kg}(\mathrm{TG})(22)$. The achieved reductions in fat mass is a realistic result from a training period with an attendance rate and training intensity as in the present study. It is reasonably to believe that the participants can maintain and maybe improve this loss of fat mass with a continuously active life style.

As the menopausal transition occurs on average at around 51 years of age (30), it can be assumed that most of the participants in the present study were of post-menopausal status (age: FG: $58 \pm 11$ yrs, TG:57 \pm 15 yrs). Muscle metabolism and anabolic signalling are affected shortly after the menopausal transition and normally associated with increased loss of muscle mass and strength (18). Connolly and colleagues (2014), whose training involved a total of 30 min/week, found no changes in LBM, in line with the present study, whereas increases in LBM of 1.2-1.4 kg have been shown in untrained pre-menopausal women after training periods involving recreational football $(14,17,21)$. However, increase in leg LBM has been shown in post-menopausal women by Seidelin and colleagues (30), who investigated the effects of a 12week floorball training programme. The training stimulus (movement patterns) in TG is comparable to the floorball training programme (29), with a high number of changes of direction and accelerations/decelerations. So, lack of change in LBM may partly be related to a low level of accelerations/decelerations in TG due to the limited playing area and therefore a lower level of muscle and ground reaction forces. Apparently, the training stimulus (including low adherence) has not been enough to induce an improvement in LBM, but the reduction in fat percentage and a maintenance of LBM is positive in improving the overall baseline health profile in FG and TG in the present study.

Similarly, the training stimulus, such as multiple changes of direction and acceleration/decelerations, did not seem to be sufficient in either group to improve BMD, but only to 
maintain whole-body bone health. In the present study, FG had a minor reduction in BMD, while there was no change in TG (indication of a minor reduction in the $95 \% \mathrm{CI}$ ). Post-menopausal women are affected by overall increased bone loss caused by the oestrogen deficiency associated with the menopause and consequent impaired bone remodelling (30). Improvement in BMD in post-menopausal women is therefore of some interest. As the adaptations in BMD vary with the type of exercise, intermittent high-intensity team-sports, which expose the bones to various muscle and ground reaction forces (odd-impact loading), have been suggested to have the highest potential for preserving BMD in post-menopausal women (19). In keeping with this, increased BMD has been found after e.g. floorball training (29). So, the small decrease in FG is hardly of clinical relevance but may be related to age-related bone loss.

Functional performance is an important variable in relation to activities of daily living. After the training interventions, there were improvements in STS performance $(\sim 21 \%$ for both groups) and $6 \mathrm{MWT}$ performance ( $8 \%$ and $11 \%$, for FG and TG, respectively). For TG the previously observed activity profile of small-sided team-sport involving dynamic activity and many changes of direction, and for FG the leg-press exercises may have contributed to the improved physical performance. This could potentially reduce accidental falls and injuries while performing daily life activities (27).

Generally, the present study reveals that it is possible to conduct team-sport training in community health centres, and the participants in both training groups had some improvements in health-related outcomes such as aerobic fitness, RHR, fat mass and functional performance.

\section{Between-group differences}

In the present study, there were no statistical differences between FG and TG in terms of improvements in aerobic fitness and RHR. Although a systematic review and meta-analysis (20) states a clear effect on e.g. aerobic fitness after recreational football, the only minor change 
in $\mathrm{TG}$, and hence no significant between-group difference from FG, is probably caused by the low-to-moderate intensity in TG. This is in line with Weston and colleagues, who found larger effects after high-intensity training (32).

Likewise, the present study found no significant differences in the development in blood pressure between the two intervention groups. The lack of significant between-group differences in blood pressure contrasts with the results of the parallel study involving male participants (22), where the change in SBP in the team-sport group was $-7.0 \mathrm{mmHg}$ different to that of the fitness group, while the change in MAP was $-4.6 \mathrm{mmHg}$ different in the teamsport group from that of the fitness group.

In FG and $\mathrm{TG}$, there were comparable improvements in physical performance, in keeping with the findings of a study by Pedersen et al. (2017) which found similar improvements in STS after training with team-sport activities and resistance training in older adults.

Furthermore, Pedersen and colleagues found that a lifestyle with-out physical activity (as a control group) lead to a decline in functional performance. The comparable improvements in physical performance in the present study were achieved with a significant difference in training attendance between the two groups ( $74 \pm 21$ and $53 \pm 25 \%$, for FG and TG, respectively), but the reasons for the low adherence among the female participants in TG is unknown.

\section{Limitations}

Our findings need to be interpreted with caution given the non-random allocation of participants to the two intervention groups and the lack of a control group maintaining a normal lifestyle during the intervention period. It is uncertain whether the results are due to the training intervention or by effect of the social environment resulting in minor changes in lifestyle habits. However, all referred subjects were provided with the same type of intervention in each training year, regardless of whether they wished to participate in the study. Additionally, both training 
periods lasted a whole year, minimising potential confounders related to differences in seasonal changes. Legal obligations prevented the $\mathrm{CHC}$ from allocating participants to a control group maintaining their normal lifestyle. The main focus of the present study was therefore to examine the development in health-related outcomes in FG, and subsequently in TG. Secondarily, the study focused on whether the standard fitness training and team-sport training were comparable. This comparison was challenged by the high drop-out rate and low adherence rate in TG. No drop-outs were due to adverse events, and while some drop-outs were caused by personal reasons others were not identified because the participants failed to attend or to respond to e-mails or phone calls. Future studies need to focus on recording reasons for low adherence and drop-outs as part of the standard protocol at the CHC. Given the low adherence in this reallife setting, it is warranted to investigate potential health effects with larger total exercise volumes. Furthermore, future studies should focus on training intensity in the real-life set-up and consider measurements of gender differences in adherence, movement patterns and intensity in the same team-sport activity divided between male, female and mixed-gender training groups. Moreover, it should be measured whether there are gender differences in the degree of flow, worry and intrinsic motivation with mixed-gender training groups.

In conclusion, the study supports the possibility of conducting team-sport training as an alternative training programme in a CHC. For sedentary women with lifestyle diseases, the two types of training resulted in a comparable development in health-related outcomes in the $\mathrm{CHC}$ set-up. Although the study was not able to show any significant differences in training outcomes between FG and TG, and failed to show similar convincing effects as reported for RCT intervention studies, the CHC could advantageously offer both fitness and team-sport training in order to provide varied training opportunities for referred citizens. However, the CHC should consider risk of a lower adherence to team-sport training among female citizens. 


\section{PRACTICAL APPLICATIONS}

In the present study, the participants trained in mixed-gender groups. Despite this, there were in-group gender differences in intensity during training in TG (training time spent at $90-100 \%$ of $\mathrm{HR}_{\max }$ (mean: 14.3 vs $6.6 \%$ ) for men and women, respectively) and attendance differences ( $60 \%$ vs $53 \%$ for men and women, respectively), which may have affected the training outcomes for the genders in TG. Similar training characteristics were observed for women and men in FG. To be able to provide sufficient stimuli to the cardiovascular system, training intensity is very important. It is therefore essential to organise the training with a continuous focus on the intensity being moderate to high for all participants. Furthermore, general gender differences in physiological adaptations $(9,14,15,28)$ and activity patterns during small-sided recreational team-sports for untrained males and females (28) should be taken into consideration when planning the training at the $\mathrm{CHC}$ and in future studies. In the study by Randers and colleagues (2010), the women had a higher number of activity changes with fewer players. So, it could be beneficial for the women in the $\mathrm{CHC}$ to conduct the specific team-sport activities with fewer active participants at any one time (e.g. 3-a-side), thereby increasing the number of activity changes and intensity level in TG. By increasing the active participation for each participant in the training, drop-out and attendance rates of female citizens in future studies might also be affected.

Overall, health effects were comparable between groups and we therefore recommend CHCs to offer team-sport training as an alternative to fitness training, with an option to choose. 


\section{REFERENCES}

1. Andersen LJ, Hansen PR, Søgaard P, Madsen JK, Bech J, Krustrup P. Improvement of systolic and diastolic heart function after physical training in sedentary women. Scand J Med Sci Sports 20 (suppl. 1), 50-7, 2010.

2. Asmussen E, Heeboll-Nielsen K. Isometric muscle strength of adult men and women. In: E. Asmussen, Fredsted A, Ryge, E, Editor. Communications from the Testing and Observation Insitute of the Danish National Association for Infantile Paralysis. Copenhagen: 1961.

3. Aspenes ST, Nilsen TIL, Skaug E-A, Bertheussen GF, Ellingsen K, Vatten L, Wislkff. Peak Oxygen Uptake and Cardiovascular Risk Factors in 4631 Healthy Women and Men. Medicine \& Science in Sports \& Exercise, Vol.43(8), p.1465-1473, 2011

4. Barene S, Krustrup P, Jackman SR, Brekke OL, Holtermann A. Do soccer and Zumba exercise improve fitness and indicators of health among female hospital employees? A 12-week RCT. Scand J Med Sci Sports 2013. doi: 10.1111/sms.12138

5. Beato M, Coratella G, Schena F, Impellizzeri FM. Effects of recreational football performed once a week ( $1 \mathrm{~h}$ per 12 weeks) on cardiovascular risk factors in middle-aged sedentary men. Science and Medicine in Foorball, 1:2, 171-177, 2017.

6. Church TS, Earnest CP, Skinner JS, Blair SN. Effects of different doses of physical activity on cardiorespiratory fitness among sedentary, overweight or obese postmenopausal. JAMA. 297:20812091, 2007

7. Connolly LJ, Scott S, Mohr M, Ermidis G, Julian R et al. Effects of small-volume soccer and vibration training on body composition, aerobic fitness, and muscular $\mathrm{PCr}$ kinetics for inactive women aged 20-45. Journal of Sport and Health Science 3, 284-292, 2014.

8. De Sousa MV, Fukui R, Krustrup P et al. Positive effects of football on fitness, lipid profile, and insulin resistance in Brazilian patients with type 2 diabetes. Scand J Med Sci Sportsm, 24 (Suppl. 1): $57-65,2014$ 
9. Donges CE, Duffield R. Effects of resistance or aerobic exercise training on total and regional body composition in sedentary overweight middle-aged adults. Applied Physiology, Nutrition, and Metabolism, 37(3), 499-509, 2012. https://doi.org/10.1139/h2012-006

10. Donnelly JE, Blair SN, Jakicic JM, Manore MM, Rankin JW, Smith BK. Appropriate physical activity intervention strategies for weight loss and prevention of weight regain for adults. Medicine and Science in Sports and Exercise, 41 (2), 459-471, 2009.

11. Fleg JL, Morrell CH, Bos AG, et al. Accelerated Longitudinal Decline of Aerobic Capacity in Healthy Older Adults. Circulation. 2005; 112: 674-682.

12. Haskell WL, Lee I-M, Pate RR et al. Physical activity and public health: updated recommendation for adults from the American College of Sports Medicine and the American Heart Association. Circulation, $116(9)$, 1081-1093, 2007.

13. Helge EW, Aagaard P, Jakobsen MD, et al. Recreational football training decreases risk factors for bone fractures in untrained premenopausal women. Scand J Med Sci Sports. 2010; 20 (Suppl. 1): $31-39$.

14. Krustrup, P., Hansen, P.R., Andersen, L.J., Jakobsen, M.D., Sundstrup, E., Randers, M.B., Christiansen, L., Helge, E.W., Pedersen, M.T., Søgaard, P., Junge A, Dvorak J, Aagaard P, Bangsbo J. Long-term musculoskeletal and cardiac health effects of recreational football and running for premenopausal women. Scandinavian Journal of Medicine \& Science in Sports 20 Suppl 1, 58-71, 2010b.

15. Krustrup P, Christensen JF, Randers MB, Pedersen H, Sundstrup E, Jakobsen, M.D., Krustrup, B.R., Nielsen, J.J., Suetta, C., Nybo, L., et al. Muscle adaptations and performance enhancements of soccer training for untrained men. European Journal of Applied Physiology 108, 1247-1258, 2010c.

16. Krustrup P, Skoradal MB, Randers MB, Weihe P, Uth J, Mortensen J, Mohr M. Broad- spectrum health improvements with one year of soccer training in inactive mildly hypertensive middle- aged women. Scand J Med Sci Sports; 1-9, 2017. 
17. Krustrup P, Helge EW, Hansen PR, Aagaard P, Hagman M, Randers MB, de Sousa M, Mohr M. Effects of recreational football on women's fitness and health: adaptations and mechanisms. European Journal of Applied Physiology 118:11-32, 2018. https://doi.org/10.1007/s00421-017-3733-7

18. Maltais ML, Desroches J, Dionne IJ. Changes in muscle mass and strength after meno-pause. J Musculoskelet Neuronal Interact. 9: 186-97, 2009.

19. Marques EA, Mota J, Carvalho J. Exercise effects on bone mineral density in older adults: a metaanalysis of randomized controlled trials. Age (Dordr) 34: 1493-515, 2012.

20. Milanović Z, Pantelić S, Čović N, Sporiš G, Mohr M, Krustrup P. Broad-spectrum physical fitness benefits of recreational football: a systematic review and metaanalysis. $\mathrm{Br}$ J Sports Med; 0:1-14, 2018. doi:10.1136/bjsports-2017-097885

21. Mohr M, Lindenskov A, Holm PM, Nielsen HP, Mortensen J, Weihe P, Krustrup P. Football training improves cardiovascular health profile in sedentary, premenopausal hypertensive women. Scandinavian Journal of Medicine and Science in Sports 24, 36-42, 2014.

22. Møller TK, Nielsen T-T, Andersen R, Lundager I, Hansen HF, Ottesen L, Krustrup P, Randers MB. "Health Effects of 12 Weeks of Team sport Training and Fitness Training in a Community Health Centre for Sedentary Men with Lifestyle Diseases," BioMed Research International, vol. 2018, Article ID 1571807, 9 pages, 2018. https://doi.org/10.1155/2018/1571807.

23. Nielsen G, Wikman JM, Jensen CJ, Schmidt JF, Gliemann L, Andersen TR. Health promotion: The impact of beliefs of health benefits, social relations and enjoyment on exercise continuation. Scand J Med Sci Sports 2014; 24 (Suppl. 1): 66-75

24. O’Donovan G, Lee I-M, Hamer M, Stamatakis E. Association of "Weekend Warrior" and other leisure time physical activity patterns with risks for All-Cause, Cardiovascular Disease, and Cancer Mortality. JAMA Intern. Med. 2017; 177 (3): 335-342

25. Ottesen L, Jeppesen RS, Krustrup BR. The development of social capital through football and running: studying an intervention program for inactive women. Scand J Med Sci Sports 20 (Suppl. 1): 118-131, 2010.

26. Pedersen BK, Saltin B. Review - evidence for prescribing exercise as therapy in 26 different chronic diseases. Scand J Med Sci Sports. 2015; 25 (Suppl. 3): 1-72. 
27. Pedersen MT, Vorup J, Nistrup A, Wikman JM, Alstrøm JM, Melcher PS, Pfister GU, Bangsbo J. Effect of team sports and resistance training on physical function, quality of life, and motivation in older adults. Scand J Med Sci Sports; 27: 852-864, 2017.

28. Randers MB, Nybo L, Petersen J, Nielsen JJ, Christiansen L, Bendiksen M, Brito J, Bangsbo J, Krustrup P. Activity profile and physiological response to football training for untrained males and females, elderly and youngsters: influence of the number of players. Scand J Med Sci Sports 20 (Suppl. 1): 14-23, 2010.

29. Seidelin K, Nyberg M, Piil P, Jørgensen NR, Hellsten Y, Bangsbo J. Adaptations with intermittent exercise training in post- and premenopausal women. Medicine \& Science in sports \& exercise: 96$105,2017$.

30. Tella SH, Gallagher JC. Prevention and treatment of postmenopausal osteoporosis. J Steroid Biochem Mol Biol. 142: 155-70, 2014.

31. Thurston, M., Green, K. Adherence to Exercise in later life: how can exercise on prescription programmes be made more effective? Health Promotion International. Vol 19. No.3. Oxford University, 2014.

32. Weston KS, Wisløff U, Coombes JS High-intensity interval training in patients with lifestyle-induced cardiometabolic disease: a systematic review and meta-analysis $\mathrm{Br} \mathrm{J}$ Sports Med 2014;48:1227-1234.

33. Wiklund P, Toss F, Weinehall L, Hallmans G, Franks PW, Nordstrom A, Nordstrom P. Abdominal and gynoid fat mass are associated with cardiovascular risk factors in men and women. Journal of Clinical Endocrinology and Metabolism,93(11), 4360-4366, 2008. https://doi.org/10.1210/jc.2008-0804.

34. HOWLEY, E.T., D.R. BASSETT, and H.G. WELCH, Criteria for maximal oxygen uptake: review and commentary. Medicine \& Science in Sports \& Exercise, 1995. 27(9): p. 1292-1301. 


\section{Figures and tables:}

TABLE 1: Effects of 12 weeks of standard fitness training and team sport training.

\section{Variable}

Age (years)

SBP $(\mathrm{mmHg})$

DBP $(\mathrm{mmHg})$

MAP (mmHg)

RHR (bpm)

Weight $(\mathrm{kg})$

$\operatorname{LBM}(\mathrm{kg})$

Fat mass $(\mathrm{kg})$

BMI $\left(\mathrm{kg} / \mathrm{m}^{2}\right)$

Fat percentage (\%)

Aerobic fitness

$\left(\mathrm{mlO}_{2} / \mathrm{kg} \cdot \mathrm{min}\right)$

WB BMC $(\mathrm{kg})$

WB BMD $\left(\mathrm{g} / \mathrm{cm}^{2}\right)$

STS (stands/30 s)

Balance (s)

6MWT (m)

Referral (\%)

Hypertension

Diabetes

BMI>35

Dyslipidaemia

Other
FG

TG

\begin{tabular}{|c|c|c|c|c|c|c|c|c|c|c|c|c|c|c|}
\hline \multirow[b]{2}{*}{$\begin{array}{c}\mathrm{N} \\
\mathrm{FG} / \mathrm{TG}\end{array}$} & \multicolumn{7}{|c|}{ FG } & \multicolumn{7}{|c|}{ TG } \\
\hline & Baseline & & Post & & $\begin{array}{l}\text { Chang } \\
\text { e score }\end{array}$ & $95 \% \mathrm{CI}$ & $P$ & Baseline & & Post & & $\begin{array}{c}\text { Change } \\
\text { score }\end{array}$ & $95 \% \mathrm{CI}$ & $\boldsymbol{P}$ \\
\hline & Mean & (SD) & $\begin{array}{c}\text { Mea } \\
\mathbf{n}\end{array}$ & (SD) & & & & Mean & (SD) & $\underset{\mathbf{n}}{\text { Mea }}$ & (SD) & & & \\
\hline
\end{tabular}

$38 / 3$

$38 / 30$

$38 / 30$

$39 / 30$

$39 / 34$

$40 / 34$

$40 / 34$

$39 / 34$

$40 / 34$

$21 / 28$

$40 / 34$

$40 / 34$

$27 / 13$

$28 / 12$

$37 / 16$

$47 / 49$

$8 / 6$

$4 / 10$

$12 / 13$

$9 / 6$

$14 / 14$
(11)

129

75

(13)

(8)

(8)

(13)

(17)

(6.8)

$126 \quad$ (16)

(16) -3

$[-7 ; 1]$

$[-3 ; 2]$

$[-3 ; 2]$

$\begin{array}{llcc}69 & (10) & -3 & {[-6 ; 0]} \\ 89 & (17) & -0.6 & {[-1.6 ; 0.3}\end{array}$

45.4

$(10.9)$

45.7

$[-0.2 ; 0.8]$

$[-1.6 ;-0.3]$

$[-0.7,0.0]$

(6.5)

44.5

(5.0)

43.7

$[-1.4,-0.3]$

[-0.6;2.0]

(4.2) $20.1 \quad$ (4.1)

$\begin{array}{llll}2.528 & (0.367) & 2.527 & (0.381)\end{array}$

$\begin{array}{llll}1.177 & (0.119) & 1.173 \quad(0.117)\end{array}$

(4)

(4) 17

(5) 3

(6)

36

(5)

(88)

(78)

523

(88)

17

9

26

19

$[-0.028 ; 0.025]$

$[-0.009 ;-0.003]$

$126 \quad(18)$

(18)

$124 \quad(16)$

$-2 \quad[-7 ; 4]$

92

(11)

$73 \quad(8)$

$[-6 ; 2]$

$[-6 ; 2]$

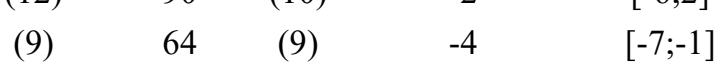

(9) 64

$-2.1 ; 0.6]$
$-0.9 ; 2.3]$

92

(21)

$92 \quad(19)$

44.0

[-1.6;0.1]

$[-0.8,0.2]$

$[-1.1,0.0]$

$[0.1 ; 1.7]$

$[-0.030 ; 0.046]$

1.185

$\begin{array}{llll}(0.488) & 2.671 & (0.483) & 0.008\end{array}$

$-0.014 ; 0.001]$

$\begin{array}{ccccr}(5) & 1.179 & (0.111) & -0.006 & {[-0.014 ; 0.001} \\ (3) & 17 & 4 & {[2 ; 6]}\end{array}$

$\begin{array}{ccc}{[2 ; 4]} & * & 14 \\ {[-0 ; 5]} & * & 37\end{array}$

(3)

$37 \quad(4)$

$[26 ; 57] * 487$

(88)

540,0

(4)

1

$[-2 ; 3]$

$[37 ; 69]$ 
Table 2: Between-group comparisons of the effects of 12 weeks of traditional fitness training $(\mathrm{FG})$ and team sport training $(\mathrm{TG})$.

\begin{tabular}{|c|c|c|c|c|}
\hline & $\begin{array}{c}\mathrm{N} \\
\mathrm{FG} / \mathrm{TG}\end{array}$ & $\begin{array}{l}\text { FG estimated } \\
\text { mean differ- } \\
\text { ence from TG }\end{array}$ & $(95 \% \mathrm{Cl})$ & P-value \\
\hline \multicolumn{5}{|l|}{ Variable } \\
\hline Age (years) & $40 / 34$ & & & \\
\hline SBP (mmHg) & $38 / 30$ & 0 & {$[-6,6]$} & 0.943 \\
\hline DBP (mmHg) & $38 / 30$ & -1 & {$[-5,2]$} & 0.368 \\
\hline MAP (mmHg) & $38 / 30$ & -1 & {$[-6,2]$} & 0.381 \\
\hline RHR (bpm) & $39 / 30$ & -1 & {$[-6,1]$} & 0.198 \\
\hline Weight (kg) & $39 / 34$ & 0.1 & {$[-1.4,1.5]$} & 0.901 \\
\hline LBM (kg) & $40 / 34$ & -2.0 & {$[-1.4,0.0]$} & 0.055 \\
\hline Fat mass $(\mathrm{kg})$ & $40 / 34$ & 0.5 & {$[-0.8,1.2]$} & 0.657 \\
\hline Fat percentage $(\%)$ & $40 / 34$ & 1.4 & {$[-0.2,1.2]$} & 0.179 \\
\hline $\begin{array}{l}\text { Aerobic fitness } \\
\left(\mathrm{mlO}_{2} / \mathrm{kg} \cdot \mathrm{min}\right)\end{array}$ & $21 / 28$ & 0.1 & {$[-1.3,1.4]$} & 0.911 \\
\hline WB BMC (kg) & $40 / 34$ & 0.502 & {$[-0.034,0.056]$} & 0.617 \\
\hline WB BMD $\left(\mathrm{g} / \mathrm{cm}^{2}\right)$ & $40 / 34$ & -0.305 & {$[-0.009,0.007]$} & 0.761 \\
\hline STS (stands/30 s) & $27 / 13$ & 0.4 & {$[-1.7,2.4]$} & 0.698 \\
\hline Balance (s) & $28 / 12$ & -0.1 & {$[-4.4,4.0]$} & 0.931 \\
\hline 6MWT (m) & $37 / 16$ & 1 & {$[-14,38]$} & 0.354 \\
\hline Attendance (\%) & $34 / 31$ & 20.7 & {$[9.2,32.1]$} & 0.001 \\
\hline
\end{tabular}




\section{Legends to tables:}

Table 1: Within-group health-related outcomes in FG and TG. Data are presented as means (SD) and change scores (95\% CI). SBP: systolic blood pressure, DBP: diastolic blood pressure, MAP: mean arterial pressure, RHR: resting heart rate, BMI: body mass index, LBM: lean body mass, WB BMC: whole-body bone mineral content, WB BMD: whole-body bone mineral density, STS: sit-to-stand test, 6MWT: 6-min walking test.

Table 2: Between-group differences $*(\mathrm{P} \leq 0.05)$. Data presented as estimated mean difference (95\% CI). SBP: systolic blood pressure, DBP: diastolic blood pressure, MAP: mean arterial pressure, RHR: resting heart rate, LBM: lean body mass, BMI: body mass index, STS: sit-tostand test, 6MWT: 6-min walking test. 


\section{Figure 1}

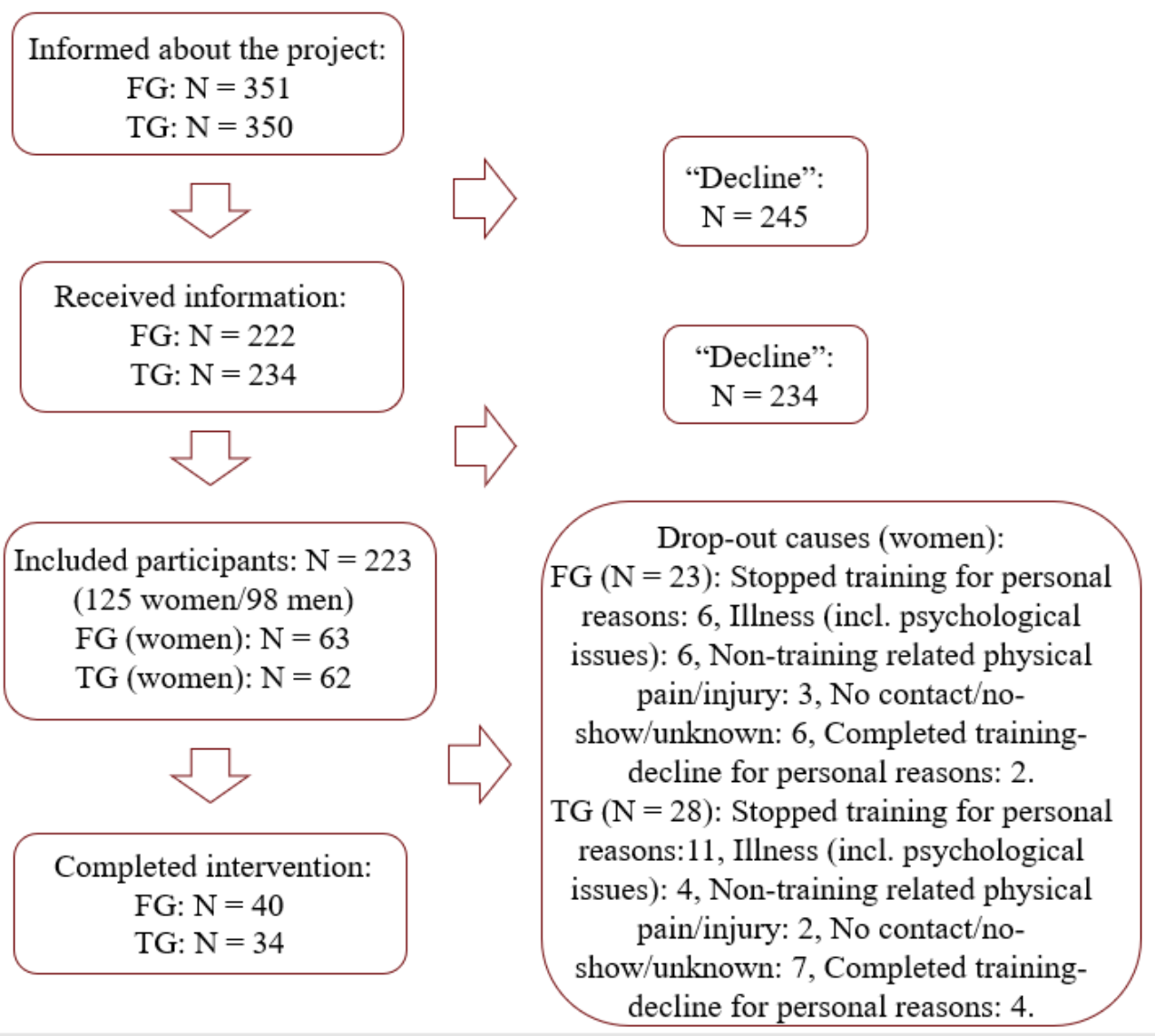


Figure 2
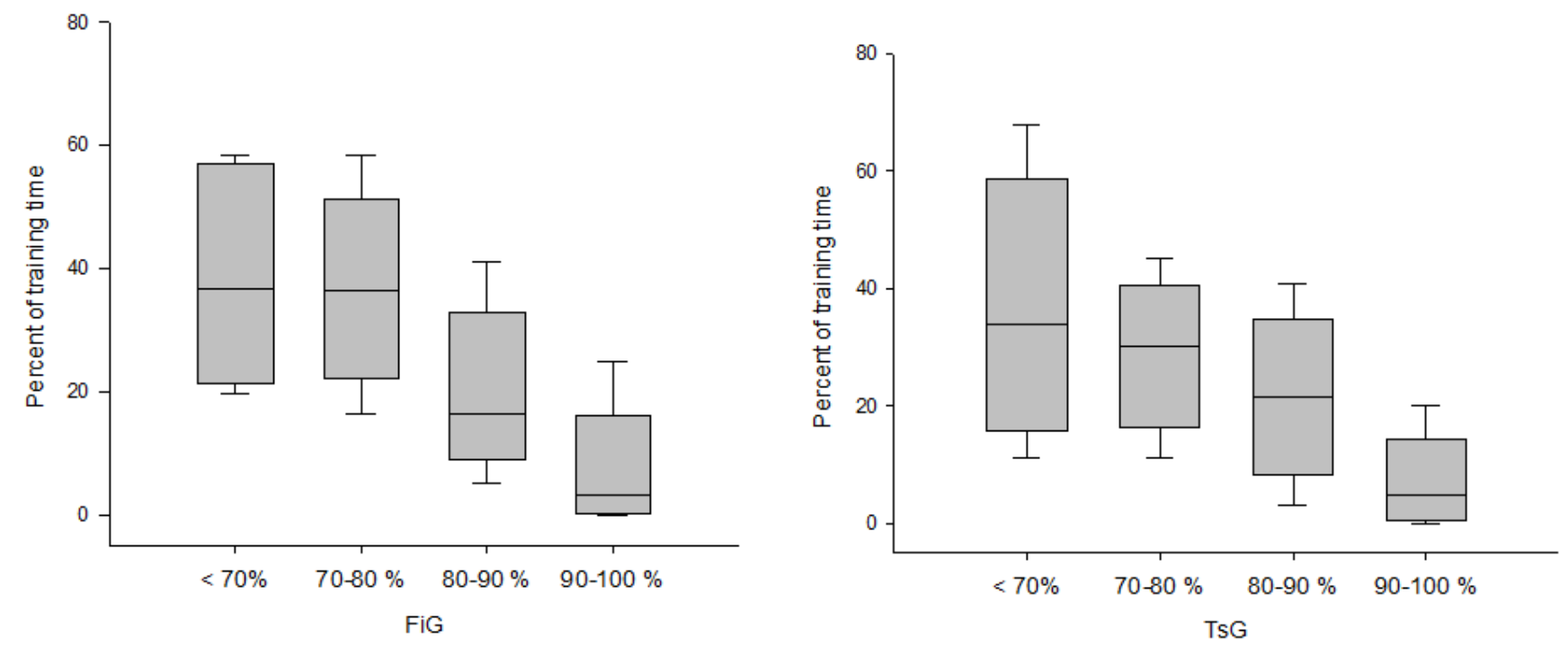

\section{Legends to figures:}

Figure 1: Recruitment process for all participants in year 1: Fitness and year 2: Team sport.

Figure 2: Training intensity - percent of $H R_{\max }$. Data are presented as median and $10^{\text {th }}, 25^{\text {th }}$, $75^{\text {th }}$ and $90^{\text {th }}$ percentile. 